\title{
On the evolution of the water ocean in the plate-mantle system
}

\author{
Takashi Nakagawa ${ }^{1,2^{*}}$, Hikaru Iwamori ${ }^{3,5}$, Ryunosuke Yanagi ${ }^{4}$ and Atsushi Nakao ${ }^{5}$
}

\begin{abstract}
Here, we investigate a possible scenario of surface seawater evolution in the numerical simulations of surface plate motion driven by mantle dynamics, including thermo-chemical convection and water migration, from the early to present-day Earth to constrain the total amount of water in the planetary system. To assess the validity of two hypotheses of the total amount of water inferred from early planetary formation processes and mineral physics, we examine the model sensitivity to the total water in the planetary system (both surface and deep interior) up to 15 ocean masses. To explain the current size of the reservoir of surface seawater, the predictions based on the numerical simulations of hydrous mantle convection suggest that the total amount of water should range from 9 to 12 ocean masses. Incorporating the dense hydrous magnesium silicate (DHMS) with a recently discovered hydrous mineral at lower mantle pressures (phase $\mathrm{H}$ ) indicates that the physical mechanism of the mantle water cycle would not be significantly influenced, but the water storage region would be expanded in addition to the mantle transition zone. The DHMS solubility field may have a limited impact on the partitioning of water in the Earth's deep mantle.
\end{abstract}

Keywords: Ocean mass, Water solubility, Dense hydrous magnesium sillicate (DHMS), Plate motion, Mantle dynamics

\section{Introduction}

Understanding the water ocean on the Earth's surface is essential for understanding the habitability of Earth-like planets (Maruyama et al. 2013). Geological records suggest that the Earth's surface seawater likely formed between $3.8 \mathrm{Ga}$ and $4.5 \mathrm{Ga}$ based on the appearance of metamorphic rocks derived from sedimentary rocks (one line of evidence that water was present on the Earth's surface) and the initiation of plate tectonics, as suggested by zircon dating (Appel et al. 1998; Maruyama and Komiya 2011; Mojzsis et al. 2001; Valley et al. 2014). However, although constraining the initiation of plate tectonics is very important for determining when water started to be transported into the deep planetary interior, this timing remains debated, with estimates ranging from 2.5 to $4.3 \mathrm{Ga}$ (Condie 2016; Hopkins et al. 2008). To reconcile such geological evidence related to the survival of the water ocean over a period of $\sim 4$ billion

\footnotetext{
* Correspondence: ntakashi@jamstec.go.jp

${ }^{1}$ Department of Mathematical Science and Advanced Technology, Japan Agency for Marine-Earth Science and Technology, 3173-25, Showa-machi, Yokohama 236-0001, Japan

${ }^{2}$ Department of Earth Sciences, University of Hong Kong, Pokfulam Road, Hong Kong, Hong Kong

Full list of author information is available at the end of the article
}

years, it is crucial to understand the size of the surface seawater reservoir. There are two hypotheses regarding the size of the reservoir that influences the evolution of the water ocean from the early to present-day Earth: (1) estimates based on cosmochemical and geochemical analyses of chondritic material and the modeling of the formation of a water ocean as a result of the solidification of a surface magma ocean (Marty 2012; Hamano et al. 2013) and (2) petrological estimates of the actual water content of the mantle (e.g., Hirschmann 2006). In the early planetary formation hypothesis, the total amount of water in the planetary system after the completion of early planetary formation or the solidification of the surface magma ocean ranges from 5 to 15 ocean masses, which means that a very large amount of water is expected to reside in the mantle (Marty et al. 2012; Hamano et al. 2013). Petrological estimates suggest that the mantle water content may range from 0.2 to 2.3 ocean masses. By adding seawater on the surface, eventually, it turns out that the total present amount of water in the planetary system should be approximately 1.2 to 3.3 ocean masses (Hirschmann 2006).

During the evolution of surface seawater over time, surface plate motions may play an important role, as has 
been implied by geological records (e.g., Maruyama and Okamoto 2007) and numerical modeling (e.g., Rüpke et al. 2004; Iwamori 2007). The evolution of surface seawater in the plate-mantle system has also been computed in semi-analytical models (Crowley et al. 2011; Sandu et al. 2011; Korenaga 2011). In such models, the partitioning of water between the surface and the deep mantle is determined by the flux balance of water uptake (regassing) by plate subduction and degassing beneath mid-ocean ridges. This modeling results in an estimate of the total water mass in the planetary system of $\sim 2$ to 3 ocean masses and consistent with petrological measurements (Hirschmann 2006).

However, our previous studies have indicated that the evolution of the mantle water mass cannot be determined with a simple regassing-degassing balance, which essentially incorporates the excess water transport associated with the dehydration reaction (Nakagawa et al. 2015; Nakagawa and Spiegelman 2017; Nakagawa and Iwamori 2017). Hence, the water solubility limit of each mantle mineral should be included to compute the excess water in the dehydration reaction. By considering this effect, our previous studies have indicated that the mantle water evolution may be strongly regulated by the water solubility limits of upper mantle minerals. In addition, the rheological properties of hydrous mantle rocks may affect the behavior of surface plate motion, with hydrous mantle conditions allowing for more vigorous surface plate motion and a much larger friction coefficient than dry mantle conditions (Nakagawa and Iwamori 2017). Such vigorous surface plate motion induced by a pseudo-plastic rheology may transport large amounts of water (i.e., several ocean masses) into the deep mantle over geologic timescales (approximately 2 billion years), and the mantle transition zone can absorb this amount of water over geologic timescales (Nakagawa and Iwamori 2017). Therefore, the total reservoir size of water at the surface and in the deep interior should be resolved in a plate-mantle system using numerical mantle convection simulations that include the water solubility limits of mantle minerals.

The issues identified in our previous studies include three model assumptions: (1) The boundary condition of mantle water transport is assumed to be an infinite reservoir of water, which is not a realistic situation. To improve the boundary condition of the mantle water transport, the lifetime and amount of water ocean in the planetary system associated with surface plate motions should be evaluated. (2) Defining the water solubility limits of mantle minerals, we only assume those of the upper mantle minerals and assign a constant value to those of the lower mantle minerals. In the lower mantle, the existence of dense hydrous magnesium silicate (DHMS) has previously been established (e.g., Ohtani et al. 2001), and according to recent mineral physics measurements, a new hydrous phase that is stable under lower mantle conditions has been found, which is a DHMS phase called "phase H." This DHMS may affect the evolution of the mantle water mass because, for instance, the solubility limit of phase $\mathrm{H}$ is very high ( 12 wt.\%; Nishi et al. 2014; Ohtani et al. 2014; Ohira et al. 2014). (3) Moreover, the pseudo-plastic yielding associated with hydrous mantle rocks is addressed as a reduction in the bulk value of the yield strength of oceanic lithosphere. More realistically, the water-weakening effect on hydrous mantle rocks likely only influences the friction coefficient, not the bulk yield strength of the oceanic lithosphere (Gerya et al. 2008).

The aim of this study is to resolve the issues that arose from our previous study and thereby reveal a possible scenario of the evolution of surface seawater in a plate-mantle system via numerical mantle convection simulations with water migration processes, including the computation of a finite amount of water at the surface, the water solubility limit of DHMS (including phase $\mathrm{H}$ ), and the improved pseudo-plastic yielding of the oceanic lithosphere associated with hydrous mantle rocks. Using this modeling approach, we can resolve which hypothesis is preferable for understanding the survival time of surface seawater.

\section{Methods/Experimental}

\section{Mantle convection simulations}

The numerical modeling of global-scale mantle dynamics with water migration has been described by Nakagawa et al. (2015) and Nakagawa and Spiegelman (2017). This process is briefly described here. We assume the thermo-chemical multiphase mantle convection of a compressible and truncated anelastic approximation in a 2D spherical annulus geometry (Hernlund and Tackley 2008). The modeled mantle can be decomposed into depleted harzburgite and enriched basaltic material composed of two-phase transition systems, i.e., olivine-spinel-bridgmanitepost-perovskite and pyroxene-garnet-bridgmanite-postperovskite, which are associated with changes in the basaltic material. A reference state for each phase transition system is computed as in Tackley (1996). All phase transition parameters can be found in Nakagawa and Tackley (2011). A partial melting effect is included to create an oceanic crust and to allow its segregation. The viscosity of the modeled mantle is dependent on temperature, pressure, water content, and yield strength and is determined via the following equations: 


$$
\begin{aligned}
& \eta_{d}=A_{d} \sum_{i, j=1}^{\text {nphase }=3,4} \Delta \eta_{i j}^{\Gamma_{i j} f} \exp \left[\frac{E_{d}+p V_{d}}{R T}\right] \\
& \eta_{w}=A_{w}\left(\frac{C_{w}}{C_{w, \text { ref }}}\right)^{-1} \sum_{i, j=1}^{\text {nphase }=3,4} \Delta \eta_{i j}^{\Gamma_{i j} f_{j}} \exp \left[\frac{E_{w}+p V_{w}}{R T}\right] \\
& \eta_{Y}=\frac{\sigma_{Y}\left(p, C_{w}\right)}{2 \dot{e}} \\
& \eta=\left(\frac{1}{\eta_{d}}+\frac{1}{\eta_{w}}+\frac{1}{\eta_{Y}}\right)^{-1}
\end{aligned}
$$

where $A_{d, w}$ is the prefactor determined by $T=1600 \mathrm{~K}$ and the ambient pressure at the surface (the subscripts $d$ and $w$ indicate dry and hydrous mantle, respectively), $E_{d, w}$ is the activation energy; $V_{d, w}$ is the activation volume; $C_{w}$ is the water content in the mantle; $C_{w, \text { ref }}$ is the reference water content and is assumed to be $620 \mathrm{ppm}$ (Arcey et al. 2005); the exponent of the prefactor, which is dependent on the water content, is based on the results of deformation experiments (Mei and Kohlstedt 2000) and is assumed to be $1 ; \Gamma_{i j}$ is the phase function; $f$ is the basaltic composition (varying from 0 to 1 ); $R$ is the gas constant $\left(8.314 \mathrm{~J} \mathrm{~K} \mathrm{~mol}^{-1}\right)$; $T$ is the temperature; $p$ is the pressure; $\sigma_{Y}\left(p, C_{w}\right)$ is the yield strength of the oceanic lithosphere, which is a function of pressure and water content; $\dot{e}$ is the second invariant of the strain rate tensor; and $\Delta \eta_{i j}$ is the viscosity jump associated with the phase transition, which is assumed to increase by 30 times during the phase transition from ringwoodite or garnet to bridgmanite.

The yield strength of oceanic lithosphere is dependent on pressure and the mantle water content and is determined as follows:

$$
\sigma_{Y}\left(p, C_{w}\right)=C_{Y}+\mu\left(C_{w}\right) p ; \mu\left(C_{w}\right)=\min \left[1,\left(\frac{C_{w}}{C_{w, \text { ref }}}\right)^{-1}\right] \mu_{0}
$$

where $\mu_{0}$ is the Byerlee-type friction coefficient. We include only the water-weakening effect caused by hydrated rocks (Gerya et al. 2008).

Another important influence of hydrated mantle rocks is the variation in density caused by hydrated mantle minerals, as noted by Nakagawa et al. (2015):

$$
\rho\left(T_{a d}, p, C, C_{w}\right)=\rho\left(T_{a d}, C, p\right)\left(1-\alpha\left(T_{a d}, C, p\right)\left(T-T_{a d}\right)\right)-\Delta \rho_{w} C_{w}
$$

where $\rho\left(T_{a d}, C, z\right)$ is the combined reference density between harzburgite and mid-ocean ridge basalt (MORB) compositions, with a $2.7 \%$ density difference, as shown in Fig. 1 (and a 3.6\% density difference between olivine- and pyroxene-related phases); $T_{a d}$ is the adiabatic temperature in the mantle; $\Delta \rho_{w}$ is the density variation due to the water content; and $C_{w}$ is the water content. Generally, the densities of hydrous minerals are less than those of dry minerals, but the value of $\Delta \rho_{w}$ is less constrained by high-pressure/ high-temperature (high P-T) experiments; the densities of hydrous minerals are generally 0.1 to $1.0 \%$ less than those of dry mantle minerals (Richard and Iwamori 2010).

To solve the equations of thermo-chemical mantle convection and to model the chemical composition, we use the numerical code of a finite-volume multigrid flow solver with tracer particles (StagYY; Tackley 2008). To determine the water migration processes, the tracer particle approach is used for the water advection process and degassing process via volcanic eruptions, and a numerical scheme involving a discrete migration velocity approximation is used for the dehydration process (Iwamori and Nakakuki 2013; Nakagawa et al. 2015; Nakao et al. 2016; Nakagawa and Spiegelman 2017). The dehydration process is modeled as the upward migration of excess water, which is defined as the difference between the actual water content and the water solubility at a certain temperature and pressure in a grid (see Fig. 2 in Nakagawa et al. 2015); this upward migration may have a velocity comparable to that of fluid movement in fully two-phase flow modeling (Wilson et al. 2014), which ranges from 0.5 to $50 \mathrm{~m} /$ year. Although this may affect the numerical resolution of the model, it should not have a significant influence on the results based on an assessment of the Appendix of Nakagawa and Iwamori (2017). Note that our model of water migration allows for migration only in the vertical direction, whereas in Wilson et al. (2014), the fluid component may migrate appreciably in the horizontal direction over several tens of kilometers near the corner of a mantle wedge. This conventional scheme seems to be valid for global-scale water circulation in a convecting mantle. In addition, we also assume the water partitioning of partially molten material, as in Nakagawa et al. (2015) and Nakagawa and Spiegelman (2017). The partition coefficient of water between solid mantle material and melt is set to 0.01 (Aubaud et al. 2008). In the numerical scheme of material transportation in Nakagawa and Iwamori (2017), two distinct compositional types of tracers are assumed, which can track the water migration for each composition separately; however, here, the chemical composition assigned to each tracer continuously varies with arbitrary melting (see Rozel et al. 2017; Lourenço et al. 2018). Hence, the water migration should be tracked using a bulk composition, which is given as:

$$
S(T, P, C)=S_{\text {Peridotite }}(T, P)(1-C)+S_{\text {Basalt }}(T, P) C
$$

where $S_{\text {peridotite }}$ and $S_{\text {basalt }}$ are the water solubilities of 


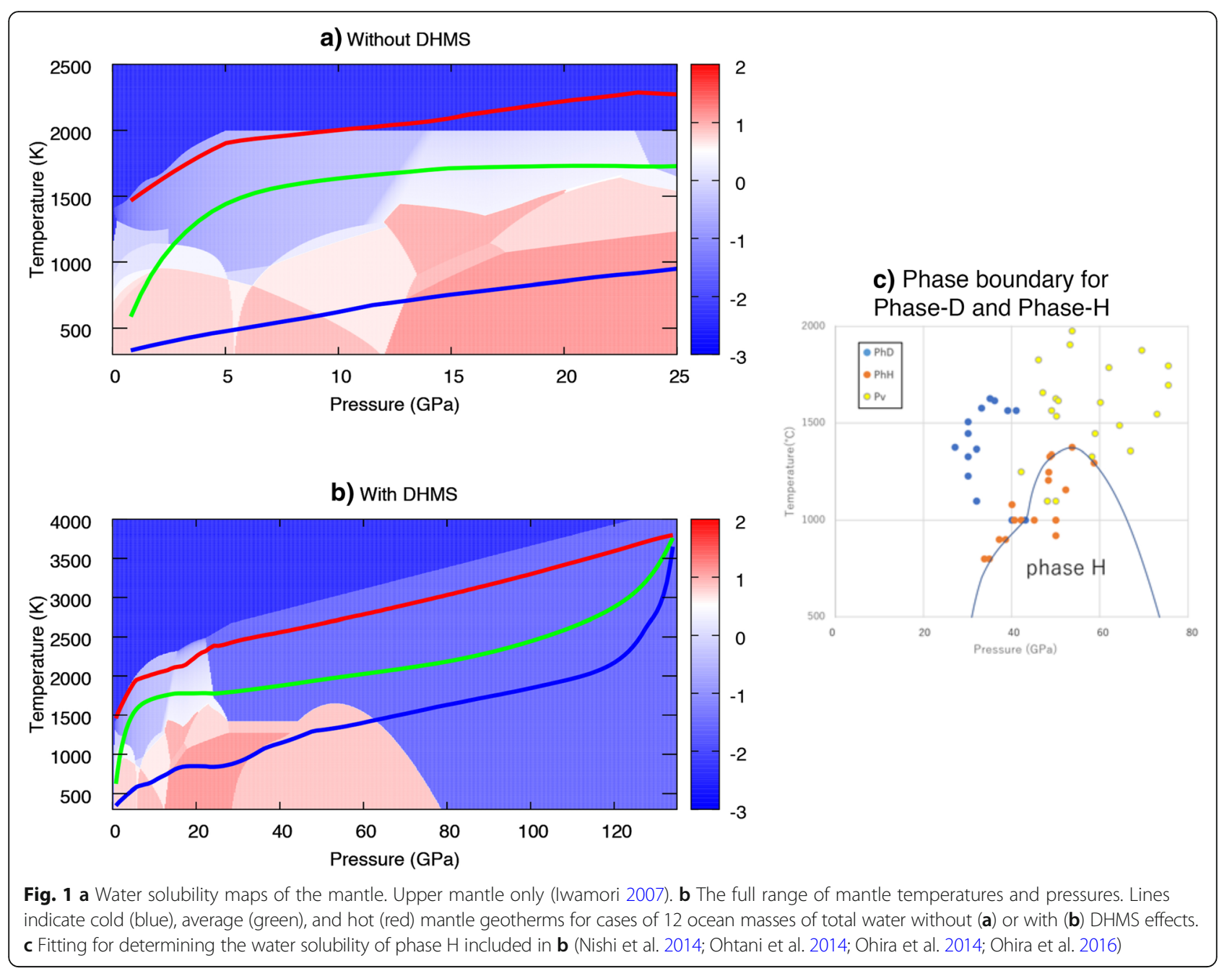

mantle peridotite and oceanic crust as functions of temperature and pressure, respectively, and $C$ is the basaltic fraction. This represents a major difference between this study and Nakagawa and Iwamori (2017). The difference between the two different melting approaches is discussed in Appendix.

The numerical setup used in this study is described as follows: 1024 (azimuthal) $\times 128$ (radial) grid points with four million tracers are used to track the chemical composition, melt fraction, and mantle water content. The boundary conditions for temperature are fixed temperatures at the surface $(300 \mathrm{~K})$ and the core-mantle boundary (CMB; $4000 \mathrm{~K})$. The initial conditions include an adiabatic temperature of $2000 \mathrm{~K}$ at the surface plus a thin thermal boundary layer (to explain the thermal boundary conditions at the surface and $\mathrm{CMB}$ ), a basaltic composition of $20 \%$, and a dry mantle (zero water content). The composition of the mantle is assumed to be uniform so that partial melting can create heterogeneous features in the mantle. The mantle can become hydrated up to the boundary conditions of the mantle water content (described in the "Computing the water ocean mass") via surface plate motion.

\section{Water solubility maps}

Figure 1 shows the maximum $\mathrm{H}_{2} \mathrm{O}$ content of the mantle peridotite system based on the work of Iwamori $(2004,2007)$ and Nakagawa et al. (2015) (Fig. 1a) and includes the stability fields of hydrous phases that are stable at lower mantle conditions (Fig. 1b). These data are used to compute the excess water migration in the convecting mantle. At the lower mantle condition, without DHMS solubility, the water solubility of the lower mantle minerals is set as 100 wt. ppm. With DHMS solubility, in addition to the existing DHMS (phases A to $\mathrm{D}$ ), because a new hydrous mineral phase has recently been discovered to exist at lower mantle pressures, i.e., "phase H" (Komabayashi and Omori 2006; Nishi et al. 2014; Ohira et al. 2014; Walter et al. 2015; Ohtani 2015), we have added the stability field of DHMS including phase $\mathrm{H}$ to the water solubility map of the mantle peridotite system (Fig. 1c). Compared to the water solubility 
map for pressures of less than 28 GPa (Iwamori 2004, 2007), few experimental results are available for pressures of greater than $28 \mathrm{GPa}$ to constrain the exact phase boundaries and the maximum amount of $\mathrm{H}_{2} \mathrm{O}$ in the peridotite system. The effect of aluminum on the stability of DHMS including phase $\mathrm{H}$ depends on the partitioning of $\mathrm{Al}$ among mantle minerals, including DHMS, phase $\mathrm{H}$, and $\delta$-AlOOH, which is currently poorly constrained. For instance, we assume that the stability of phase $\mathrm{H}$ in the natural peridotite system is similar to that of the pure $\mathrm{MgSiO}_{4} \mathrm{H}_{2}$ phase $\mathrm{H}$ (Ohira et al. 2016), which can be used to establish a minimum P-T stability range. Considering the bulk peridotite composition and the maximum modal amount of phase $\mathrm{H}$ in the peridotite system, we estimate that the maximum $\mathrm{H}_{2} \mathrm{O}$ content in the phase $\mathrm{H}$-bearing $\mathrm{P}-\mathrm{T}$ range is 8 wt.\%. At pressures and temperatures higher than the stability field of DHMS with phase $\mathrm{H}$, we set a maximum $\mathrm{H}_{2} \mathrm{O}$ content of 100 ppm below the solidus (e.g., Panero et al. 2015) and 0 ppm above the solidus, as in Nakagawa et al. (2015).

\section{Computing the water ocean mass}

In a previous study (Nakagawa and Iwamori 2017), we assumed a fixed boundary condition for mantle water migration in terms of the water ocean mass, such as a fixed value of $1.4 \times 10^{21} \mathrm{~kg}$ (one ocean mass). This is not very realistic for understanding geologic records of the evolution of the water ocean associated with surface plate motion (e.g., Maruyama et al. 2013). To formulate a finite reservoir of surface seawater with a box model assumption, the mass of the water reservoir can be computed as:

$$
X_{w, s}=X_{w, \text { total }}-X_{w, m}\left(F_{R}, F_{H}, F_{\mathrm{G}}\right)
$$

where $X_{w, s}$ is the mass of the water ocean, $X_{w \text {, total }}$ is the mass of the total amount of water in the system, and $X_{w}$, $m$ is the mass of mantle water as a function of regassing $\left(F_{R}\right)$, dehydration $\left(F_{H}\right)$, and degassing $\left(F_{G}\right)$. The boundary condition of mantle water migration at the surface is described as follows:

$$
C_{w}(\text { surface })=\left\{\begin{array}{c}
C_{w, \text { sol }}(300 K, \text { surface }) \text { if } X_{w, s}>0 \\
0 \text { if } X_{w, s}=0
\end{array}\right.
$$

where $C_{w}$, sol $(300 K$, surface) is the water solubility of mantle rocks at the surface.

\section{Results}

All physical parameters used in this study are listed in Table 1 . This study examines a total of 20 cases that vary with the total amount of water in the planetary system (3 to 15 ocean masses) and the strength of the oceanic

\begin{tabular}{|c|c|c|}
\hline Symbol & Meaning & Value \\
\hline$\eta_{0}$ & Reference viscosity & $10^{21}$ (Pa s) \\
\hline$\Delta \eta$ & Viscosity jump & 30 \\
\hline$\rho_{0}$ & Reference density & $3300\left(\mathrm{~kg} \mathrm{~m}^{-3}\right)$ \\
\hline$\Delta o_{w}$ & $\begin{array}{l}\text { Density anomalies due to } \\
\text { mantle water content }\end{array}$ & $4.125\left(\mathrm{~kg} \mathrm{~m}^{-3}\right)$ \\
\hline$g_{0}$ & Gravity & $9.8\left(\mathrm{~m} \mathrm{~s}^{-2}\right)$ \\
\hline$a_{0}$ & Reference thermal expansivity & $5 \times 10^{-5}\left(K^{-1}\right)$ \\
\hline$\kappa_{0}$ & Reference thermal diffusivity & $7 \times 10^{-7}\left(\mathrm{~m}^{2} \mathrm{~s}^{-1}\right)$ \\
\hline$\Delta T_{s a}$ & Temperature scale & $2500(K)$ \\
\hline$T_{s}$ & Surface temperature & $300(K)$ \\
\hline$T_{C M B}$ & Temperature at the CMB & $4000(K)$ \\
\hline$C_{p}$ & Heat capacity & $1250\left(\mathrm{~J} \mathrm{~kg}{ }^{-1} \mathrm{~K}^{-1}\right)$ \\
\hline$L_{m}$ & Latent heat & $6.25 \times 10^{5}\left(\mathrm{~J} \mathrm{~kg}^{-1}\right)$ \\
\hline$H$ & Internal heating rate & $5.2 \times 10^{-12}\left(\mathrm{~W} \mathrm{~kg}^{-1}\right)$ \\
\hline$C_{Y}$ & Cohesion stress & $10(\mathrm{MPa})$ \\
\hline$E_{d}$ & Activation energy of dry mantle & $290\left(\mathrm{~kJ} \mathrm{~mol}{ }^{-1}\right)$ \\
\hline$V_{d}$ & Activation volume of dry mantle & $2.4 \times 10^{-6}\left(\mathrm{~m}^{3} \mathrm{~mol}^{-1}\right)$ \\
\hline$E_{w}$ & Activation energy of wet mantle & $380\left(\mathrm{~kJ} \mathrm{~mol}{ }^{-1}\right)$ \\
\hline$V_{w}$ & Activation volume of wet mantle & $4 \times 10^{-6}\left(\mathrm{~m}^{3} \mathrm{~mol}^{-1}\right)$ \\
\hline$R$ & Gas constant & $8.134\left(\mathrm{~J} \mathrm{~K}^{-1} \mathrm{~mol}^{-1}\right)$ \\
\hline D & Thickness of mantle & $2890(\mathrm{~km})$ \\
\hline
\end{tabular}

Table 1 Physical parameters

The Rayleigh number is computed as $\rho_{0} g_{0} a_{0} \Delta T_{s a} D^{3} / K_{0} \eta_{0} \sim 1.4 \times 10^{8}$ with values listed in Table 1. Activation energy and volume for dry mantle are taken from Yamazaki and Karato (2001) and for wet mantle are taken from Korenaga and Karato (2008). Results are not changed with rheological parameters taken from Karato and Wu (1993) for wet mantle. The latent heat shown here is used for temperature feedback caused by partial melting (Xie and Tackley 2004)

lithosphere. The parameters used in each case are listed in Table 2. First, we examine the effect of DHMS in conjunction with a large reservoir of surface seawater. Second, we examine the two hypotheses of the total amount of water in the planetary system. Third, the strength of the oceanic lithosphere is investigated by varying the friction coefficient $\left(\mu_{0}\right)$ from 0.1 to 0.6 . This range represents the suggested range of lithospheric strength inferred from island loading (0.2-0.75; Zhong and Watts 2013). The minimum friction coefficient is based on the value associated with stable plate-like behavior in a dry mantle convection model ( 0.13; Moresi and Solomatov 1998). All numerical simulations are performed for approximately 4.6 billion years.

\section{Chemical-hydrous structure with effects of DHMS}

Figure 2 shows the chemical-hydrous structure of the mantle with and without the water solubility effects of DHMS at $t=4.6$ billion years and for $\mu_{0}=0.2$, with an assumed total water volume of 12 ocean masses in the planetary system (exosphere plus interior). In both cases, extremely high-viscosity structures are found in the 
Table 2 Run summary

\begin{tabular}{llll}
\hline Run \# & Total water mass & $\boldsymbol{\mu}_{\mathbf{0}}$ & Phase H solubility \\
\hline 1 & 12 & 0.2 & No \\
2 & 12 & 0.2 & Yes \\
3 & 3 & 0.2 & No \\
4 & 6 & 0.2 & Yes \\
5 & 9 & 0.2 & Yes \\
6 & 15 & 0.2 & Yes \\
7 & 12 & 0.1 & Yes \\
8 & 12 & 0.3 & Yes \\
9 & 12 & 0.6 & Yes \\
\hline
\end{tabular}

The total water mass is normalized by mass of surface sea water at the present-day Earth $\left(1.4 \times 10^{21}(\mathrm{~kg})\right.$; Genda (2016))

lower mantle due to the high efficiency of heat transfer of hydrous mantle convection (Nakagawa et al. 2015). Without DHMS, we assume that the water solubility of the lower mantle minerals is set as 100 wt. ppm. Without DHMS solubility, the dry mantle transition zone corresponds to upwelling plumes, which can have a temperature that is hotter than $2000 \mathrm{~K}$. As shown in Fig. 6c of Nakagawa and Iwamori (2017), the high temperatures associated with mantle plumes correspond to water contents of zero. Incorporating the DHMS stability field into the water solubility maps (see Fig. 1a, b) reveals that the high-temperature mantle plumes may have a certain water content, unlike in the case without DHMS solubility limits. Another major difference between the cases with and without DHMS solubility is that the hydrated region at a depth of $660 \mathrm{~km}$ expands to the uppermost lower mantle in cold downwelling regions because of the high water content of DHMS (see arrows at the bottom of Fig. 2). Since we also assume that a density reduction occurs due to the hydration of

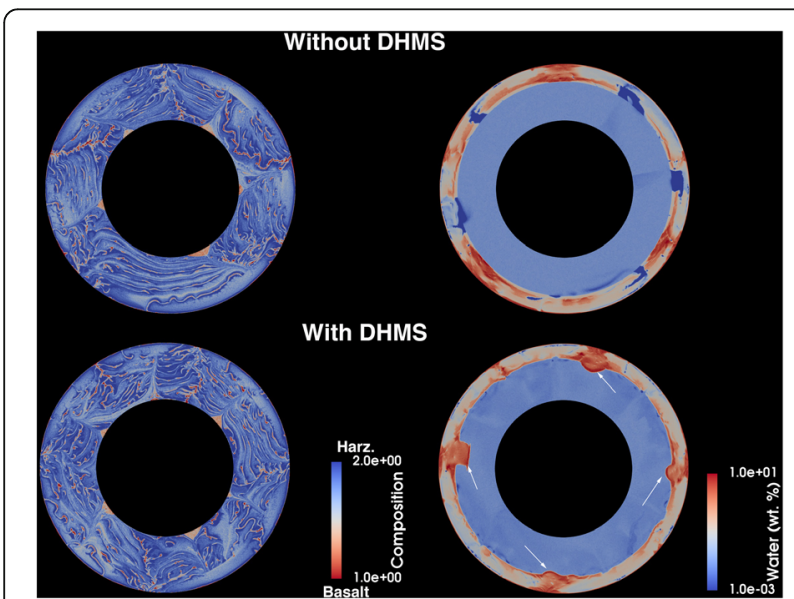

Fig. 2 Compositional (left) and hydrous (right) structures at $t=4.6$ billion years. Top: without phase H (old look-up database); bottom: with DHMS solubility effects (new look-up database) the mantle minerals (Nakagawa et al. 2015), smaller-scale basaltic piles are found in the deep mantle compared to those generated by dry mantle convection (e.g., Nakagawa and Tackley 2011).

To confirm how DHMS affects the mantle water content, Fig. 3 shows the 1D horizontally averaged mantle water content corresponding to the hydrous structure in Fig. 2. Without the effects of DHMS, the mantle transition zone is the main water absorber; however, with the effects of DHMS, an additional region of high water content can be found at depths of up to $\sim 1500 \mathrm{~km}$. The water content in the mantle transition zone in these cases ranges from 0.1 to $1.0 \mathrm{wt} . \%$. This range is similar to those inferred from the electrical conductivity structure of the mantle transition zone (e.g., Kelbert et al. 2009) and from seismic imaging (Houser 2016; Schmandt et al. 2014). Moreover, these results also seem to be consistent with the measurements of the water content of diamond inclusions in wadsleyite (Pearson et al. 2014). To confirm the cause of the water enhancement in DHMS found in Fig. 3, Fig. 1a, b shows the water solubility maps on which the $1 \mathrm{D}$ vertical structures of temperature have been plotted. Comparing a cold temperature profile with the water solubility map in Fig. $1 \mathrm{~b}$ appears to indicate that phase $\mathrm{H}$ appears in the temperature profile at a depth of $\sim 1500 \mathrm{~km}$ (corresponding to a pressure of approximately $60 \mathrm{GPa}$ ).

\section{Water mass evolution and plate-like behavior: with and without DHMS}

Figure 4 shows the temporal variations in the surface water mass and surface mobility that can be computed using the ratio of the surface velocity to the root mean square velocity in the entire mantle with and without DHMS, as shown in Fig. 2. Over 4.6 billion years, the surface seawater comprises 2.2 ocean masses without DHMS and 1.2 ocean masses with DHMS. Both cases are started with 12 ocean masses in total amount of

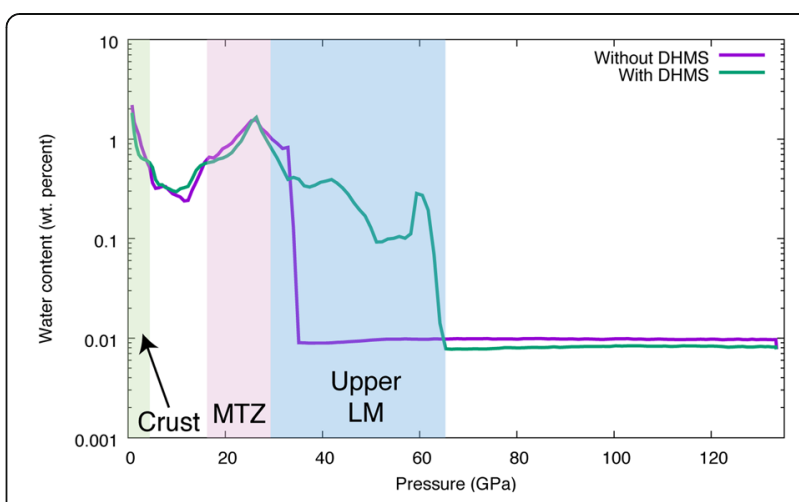

Fig. 3 1D horizontally averaged mantle water content with and without DHMS solubility as a function of pressure scaled as GPa units 


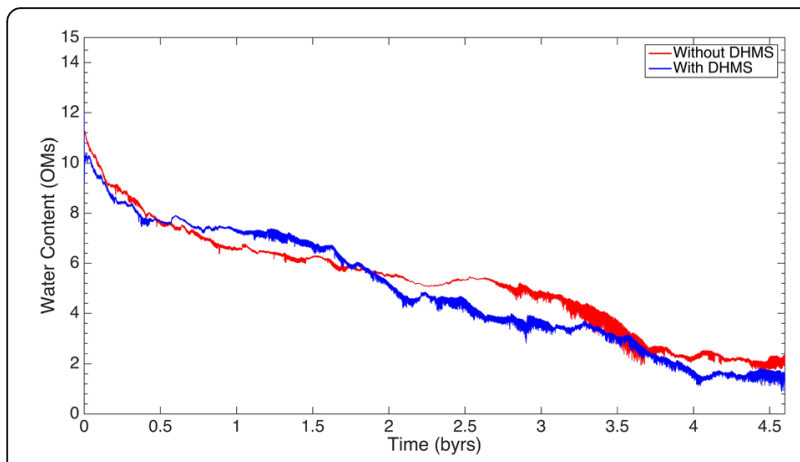

Fig. 4 Temporal variations in the mass of surface seawater with and without DHMS effects

water. This means that, for the mantle water mass, 9.8 ocean masses without DHMS and 10.8 ocean masses with DHMS are absorbed in the mantle. Therefore, when the DHMS effect is included, this water is more likely to be partitioned into the deep mantle to match the constraint on the present-day Earth's ocean mass. In Figs. $1 \mathrm{~b}$ and 3, with DHMS, more water can be absorbed in the upper lower mantle compared to a case without DHMS, which is caused by phase $D$ and/or phase $H$. However, as shown in Table 3 of Iwamori (2007), the maximum amount of water that can be stored is 9 to 11 ocean masses, assuming that the maximum $\mathrm{H}_{2} \mathrm{O}$ content in the lower mantle is $100 \mathrm{ppm}$ and assuming an average geotherm corresponding to that beneath $60 \mathrm{Ma}$ oceanic lithosphere with a mantle potential temperature of $1300{ }^{\circ} \mathrm{C}$ (Iwamori 2007). This may suggest that the DHMS plays a minor role in the mantle water mass, which contributes at most to $\sim 1$ ocean mass of water mass in the whole mantle because the effects of DHMS only appeared in the cold subducting regions.

Figure 5 shows the mantle water fluxes (ingassing, dehydration, and degassing) as a function of time with and without DHMS. The procedures for computing these water fluxes can be found in Nakagawa and Iwamori (2017) and Nakagawa and Spiegelman (2017). They are given as follows:

$$
\begin{aligned}
& F_{R}=\left\{\begin{array}{r}
\int_{S} \rho_{m} u_{z} C_{w} d S\left(\text { if } u_{z}<0\right) \\
0\left(\text { if } u_{z} \geq 0\right)
\end{array}\right. \\
& F_{G}=\dot{M}_{\text {erupt }} C_{w, \text { erupt }} \\
& F_{E}=\int_{S} \rho_{m} C_{w, \text { ex }} u_{f} d S
\end{aligned}
$$

where $\rho_{m}$ is the mantle density; $\dot{M}_{\text {erupt }}$ is the total mass of erupted material; $C_{w}$ is the water content; $u_{z}$ is the radial velocity; $C_{w \text {,erupt }}$ is the water content of the erupted material, which is equivalent to the water content of the molten material; $C_{w \text {, ex }}$ is the excess water content relative to the water solubility; and $u_{f}$ is the conventional form of fluid migration velocity expressed numerically,

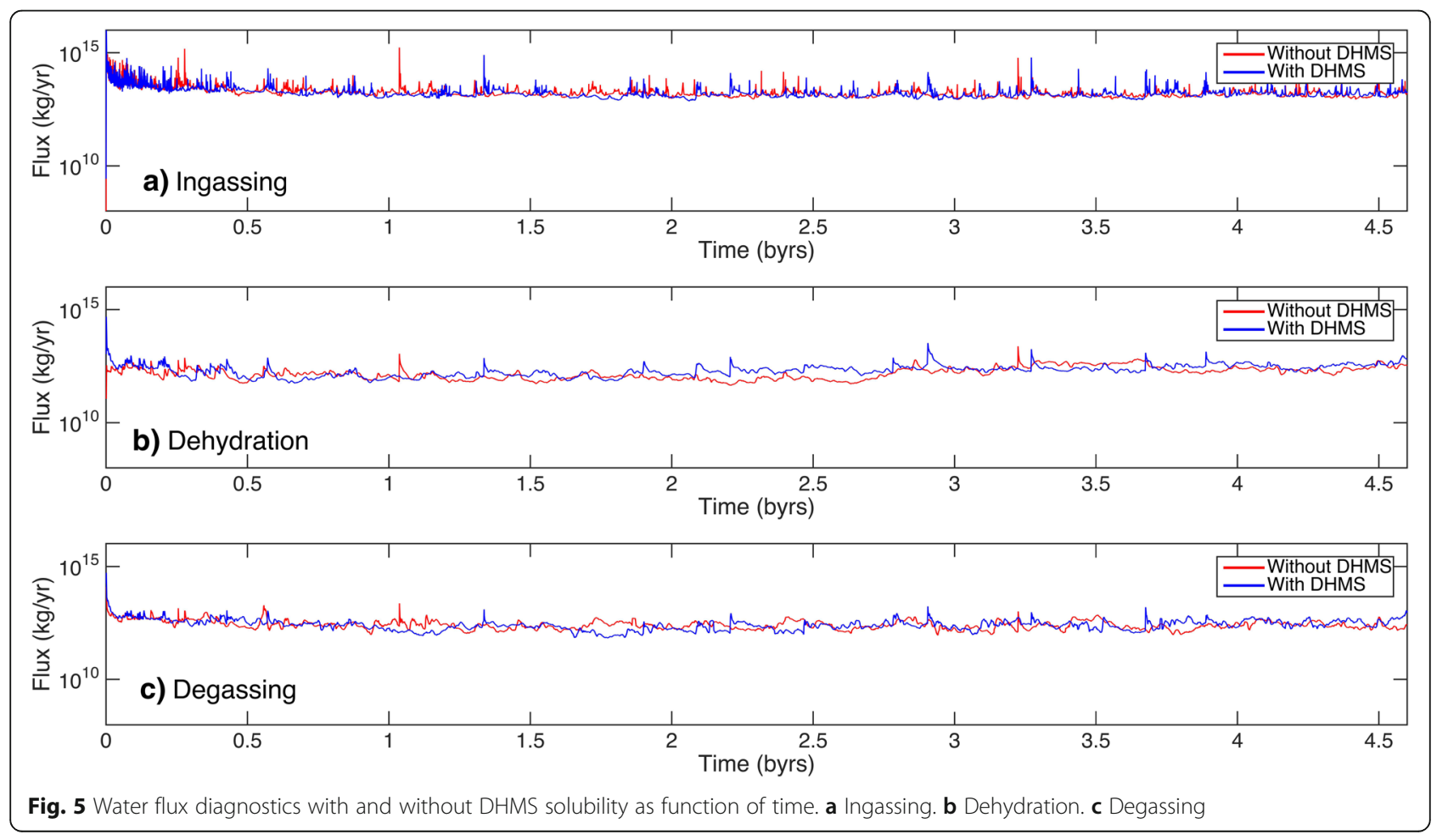


which is computed as the ratio of the radial grid spacing to the time step size but is not very sensitive to the grid spacing shown in the Appendix of Nakagawa and Iwamori (2017), and the subscripts of those fluxes are $R=$ ingassing, $G=$ degassing, and $E=$ dehydration. Basically, the uptake of water from the surface reservoir by plate subduction is the dominant flux process, with a magnitude on the order of $10^{13} \mathrm{~kg} /$ year, with the two other fluxes involving the release of water at the surface of approximately an order of magnitude lower than that involved in the uptake process. Thus, the surface seawater is gradually reduced by the ingassing process with surface plate motion. These profiles of water fluxes without DHMS are not very different from those in a case with the DHMS solubility field because the effective depth of the mantle water cycle associated with those fluxes is approximately 150 to $200 \mathrm{~km}$ (Nakagawa and Spiegelman 2017). This means that the DHMS solubility field is less sensitive to the physical processes of the mantle water cycle.

To assess the model sensitivities to the total amount of water in the planetary system, Fig. 6 shows the temporal variations in the surface seawater, mantle mass, and surface mobility with DHMS, which indicate that the surface seawater completely dries up before reaching the age of the Earth for a total amount of water of less than nine ocean masses. This implies that the total amount of water in the planetary system should be preferably in about 12 ocean masses, for the surface seawater to be consistent with the surface seawater on the present-day Earth. This preferred amount of water coincides with the storage capacity of the silicate mantle, as mentioned above (Iwamori 2007), although the mantle temperature reproduced in this study (e.g., Fig. 1) is lower than the $60 \mathrm{Ma}$ geotherm assumed by Iwamori (2007). This indicates that (1) DHMS in the lower mantle, which was ignored in Iwamori (2007), plays a minor role, and (2) the present-day mantle could contain a maximum amount of water due to continuous hydration (Fig. 6). As discussed in the the "Introduction," the total amount of water in the Earth system has been estimated to be 1.2 to 3.3 ocean masses, which is based on the water contents of oceanic basalts (mid-ocean ridge basalts (MORB) and ocean island basalts (OIB)) and assumes that the entire mantle is sampled by MORB and OIB (Hirschmann 2006). While the upper mantle comprises the MORB source, OIB likely represents only a part of the crust-mantle cycling system (e.g., White and Hofmann 1982; Christensen and Hofmann 1994). The apparent difference in the estimated amount of water (i.e., $10-12$ vs. $1.2-3.3$ ocean masses) could be due to the regions that are not sampled by either MORB or OIB.

Regarding the surface mobility, which is one diagnostic for assessing the occurrence of plate-like behavior and is computed as the ratio of surface velocity to the root

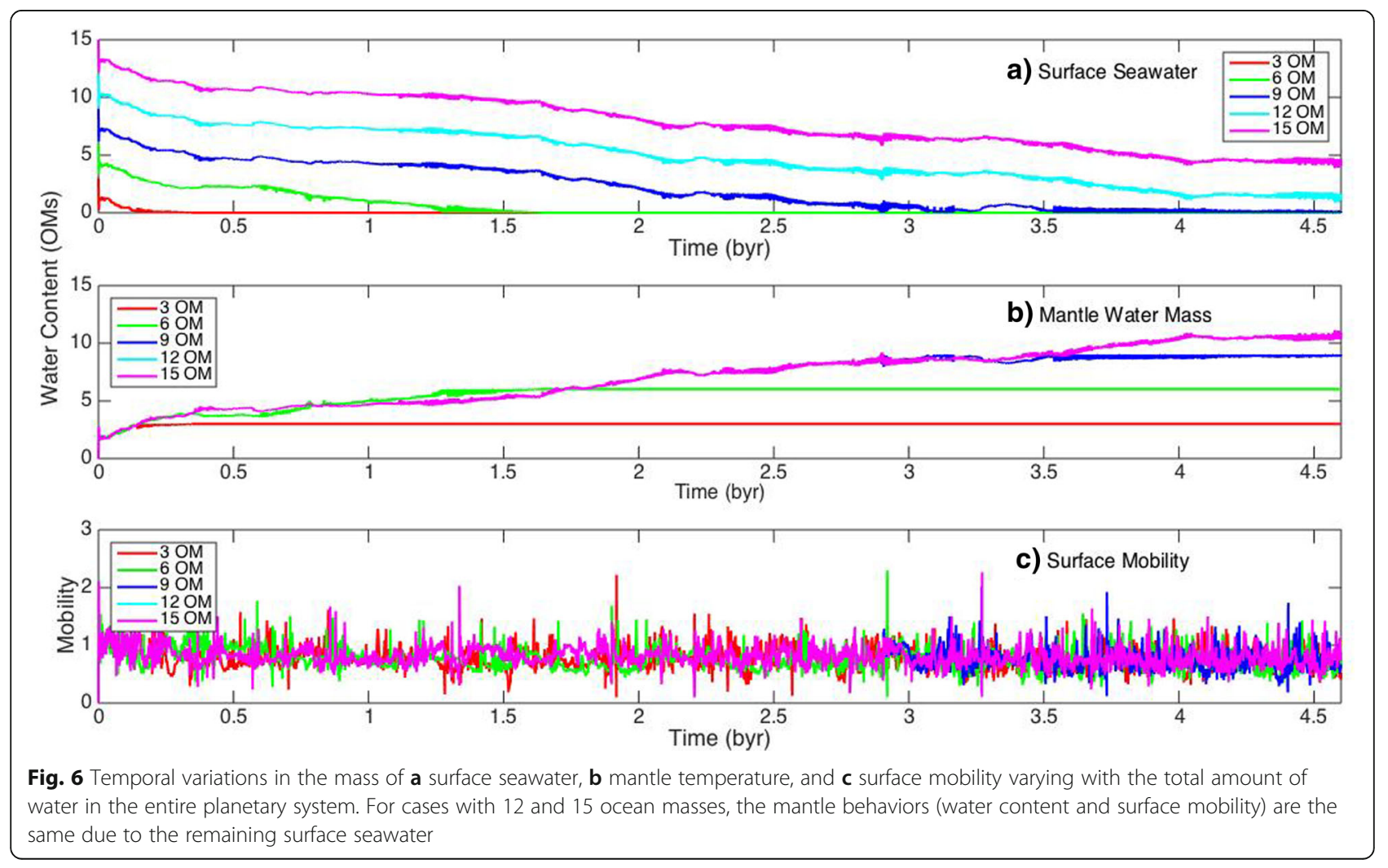


mean square of the convective velocity of the entire mantle (bottom of Fig. 6), it appears to not change very much after all the surface seawater is absorbed into the deep mantle. This suggests that the surface seawater found on the Earth's surface is not strongly correlated with the occurrence of surface plate motion. To confirm this hypothesis, Fig. 7 shows the sensitivity of the total amount of water to water fluxes, which indicates that the degassing flux is still active when the surface seawater is exhausted. This suggests that the surface seawater could be regenerated with mantle degassing, and the water-weakening effect is still valid but that it is immediately returned to the deep mantle via plate subduction. Therefore, surface plate motion will still be very active even if all surface seawater is exhausted.

\section{Water mass evolution: model sensitivity to the strength of the oceanic lithosphere}

Figure 8 shows the temporal variations in both the surface and mantle water masses over 4.6 billion years for different friction coefficients $(0.1,0.2,0.3$, and 0.6$)$ corresponding to different strengths of oceanic lithosphere. All of the cases shown here include the solubility effects of DHMS. For weaker oceanic lithosphere $\left(\mu_{0}=0.1\right.$ and 0.2 ), the surface seawater can be partitioned with a similar value as the present-day Earth's ocean mass over 4 billion years. On the other hand, for stronger oceanic lithosphere $\left(\mu_{0}=0.3\right.$ and 0.6$)$, the amount of surface seawater still remains at approximately five ocean masses. This mechanism can be explained by the mass-averaged temperature profile as a function of time as shown in Fig. 7b, c. In weaker oceanic lithosphere, heat transport is more efficient due to the vigorous surface plate motion and large number of plate boundaries (Nakagawa and Iwamori 2017). The mantle temperature is cold enough to pass into the water solubility field of DHMS with phase H. However, stronger oceanic lithosphere cases indicate higher mantle temperatures, so that the mantle temperature does not pass into the water solubility field of DHMS. To confirm this implication, Fig. 9 shows the 1D horizontally averaged mantle water content as a function of pressure. For weaker oceanic lithosphere, a high water content region can be found at both the mantle transition zone and upper lower mantle corresponding to DHMS solubility. In contrast, for stronger oceanic lithosphere, water enhancement is only found in the mantle transition zone. This is caused by the difference in mantle temperatures shown in Fig. 7b and the heat transfer efficiency of plate-mantle dynamics.

\section{Discussion}

\section{Findings}

The findings from this study are described as follows:

1. The presence of DHMS may have a limited impact

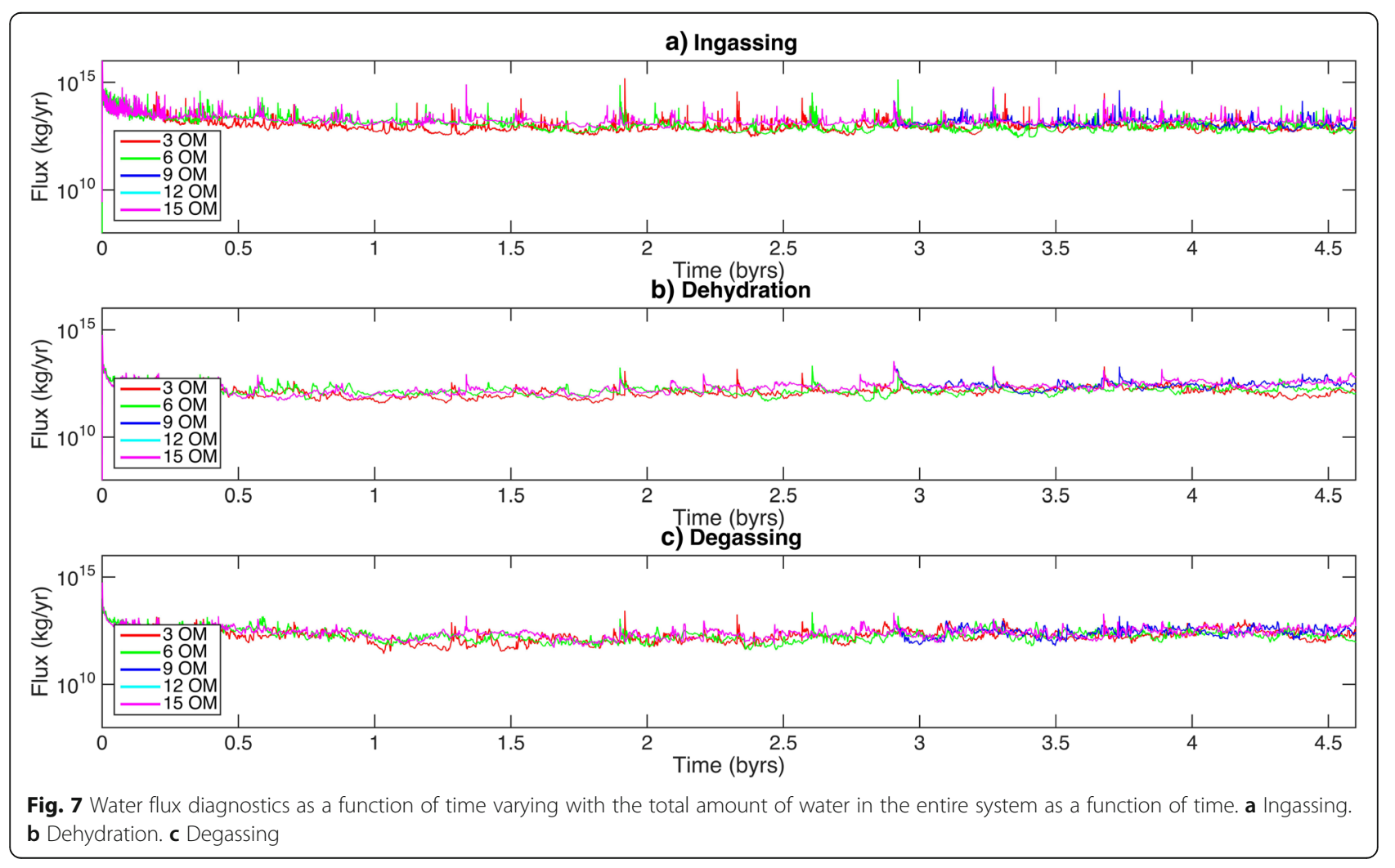



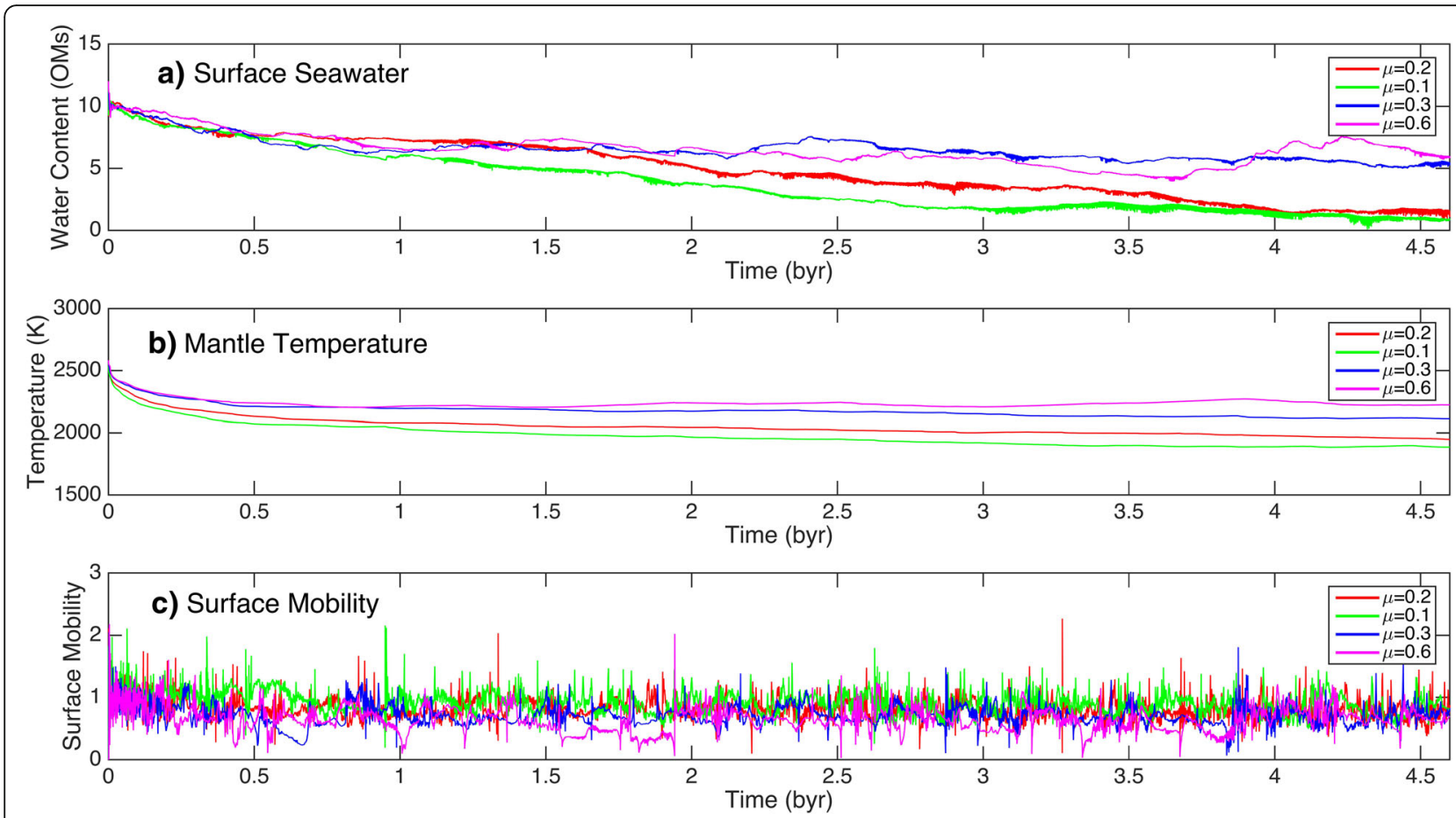

Fig. 8 Temporal variations in the mass of a surface seawater, $\mathbf{b}$ mantle temperature, and $\mathbf{c}$ surface mobility varying with the friction coefficient of the yield strength of the oceanic lithosphere. The total amount of water is fixed as 12 ocean masses

on the evolution of surface seawater but is not very different from that of the physical processes of the mantle water cycle. The physical mechanism of the mantle water cycle is strongly regulated by the choke point of the water solubility of the mantle minerals (Nakagawa and Spiegelman 2017). However, the DHMS may play some role in expanding the storage region of water transported by plate subduction. Quantitatively, a water reservoir with a water content of $0.1 \mathrm{wt} . \%$ is located in the upper lower mantle due to DHMS solubility. To discuss the consistency between this amount and the realistic hydrous

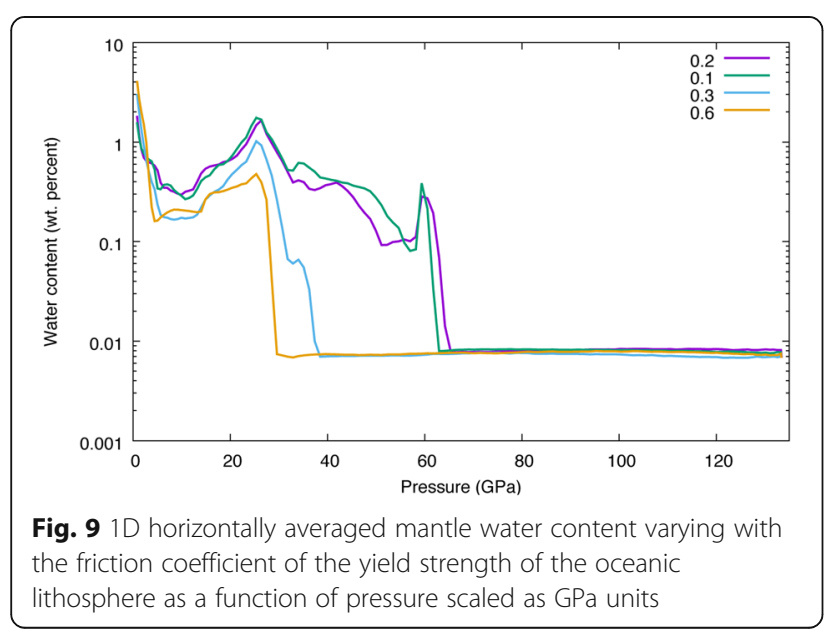

conditions of the Earth, more observational and experimental measurements are required.

2. The survival time of surface seawater is dependent on the total amount of water in the entire planetary system and the strength of the oceanic lithosphere. To partition water into the surface reservoir with the present-day mass of the surface seawater on the Earth's surface, the entire planetary system should contain ten ocean masses or more, although more accurate knowledge about mantle hydrous phases is required. However, the total amount of water in the planetary system would be reduced if the strength of the oceanic lithosphere was slightly stronger but a large amount of water $(\sim 7$ ocean masses) was absorbed in the deep mantle. This finding, i.e., that a large amount of water is required for the early Earth, is consistent with an estimate derived from the experimental measurements of chondritic material and inferences based on the solidification of the surface magma ocean during early planetary formation (Marty 2012; Hamano et al. 2013). The total absorbed amount of water in the mantle is also consistent with the estimate obtained based on the material properties of mantle rocks along the realistic geotherm (Iwamori 2007). These results are consistent because the water budget in the mantle is primarily controlled by the water released by dehydration reactions rather than that released by 
degassing effects, which has been the main focus of simplified models of hydrous mantle evolution (Franck and Bounama 2001; Rüpke et al. 2004; Crowley et al. 2011; Sandu et al. 2011; Korenaga 2011)

\section{DHMS and other potential mechanisms of water transport into the deep mantle}

First, the stability fields of DHMS including phase $\mathrm{H}$ that are stable under lower mantle pressure conditions are poorly constrained, as was described earlier in the "Water solubility map" section. In this study, our stability field of phase $\mathrm{H}$ corresponds to that of Ohira et al. (2016) and features a minimum stability field of 70 to $80 \mathrm{GPa}$. If the stability field is raised to more than $100 \mathrm{GPa}$ and higher temperatures, more water can be transported via plate subduction, which may shorten the lifetime of surface seawater; to achieve an Earth-like planet, more water is required in the system.

Second, other potential host minerals of water exist in the deep mantle, such as $\delta$-AlOOH (Ohira et al. 2014) or pyrite-type FeOOH (Nishi et al. 2017). These minerals appear to be stable at typical lower mantle temperatures and pressures. However, the amount of water that these minerals can retain in the deep mantle remains unclear. The possible water solubilities of the lower mantle minerals, including phase $\mathrm{H}, \delta$-AlOOH, and pyrite-type $\mathrm{FeOOH}$, which could potentially be accurately determined via experiments, could greatly influence the survival time of surface seawater. The inclusion of additional lower mantle minerals could result in a much shorter seawater survival time than that observed in the cases examined in this study. Note that the volume-averaged water content of the lower mantle is be expected to be $\sim 100 \mathrm{ppm}$ or less (Karato 2011; Panero et al. 2015), but these estimates remain highly controversial and are dependent on identifying the possible host minerals of water in the deep lower mantle. Therefore, these estimates should be determined more quantitatively to resolve this issue.

Third, a hydrogen diffusion mechanism is also a significant process in the mantle water cycle (Richard et al. 2002, 2006) and is still unresolved in this study. Numerical modeling results suggest that hydrogen diffusion seems to saturate the mantle with water on a much shorter timescale than that without incorporating hydrogen diffusion (Nakagawa 2017). The incorporation of a water-saturated mantle leads to a steady state in the evolution of surface seawater induced by the mantle water cycle. As a result, the lifetime of surface seawater can be expected to be longer in this study.

Moreover, the rheological properties of the hydrous lower mantle are highly uncertain because of the difficulty of experimental determination, even for dry mantle conditions (e.g., Girard et al. 2016). Under dry mantle conditions, the lower mantle minerals are expected to exhibit the shear localization mechanism with diffusion creep deformation (Girard et al. 2016). However, it is unclear whether this type of deformation mechanism occurs under hydrous lower mantle conditions. If the rheological properties of the lower mantle are similar to those of the upper mantle, more water could be transported into the deep mantle, and the lifetime of surface seawater may be shorter due to the more vigorous convective dynamics in the lower mantle.

\section{Strength of the oceanic lithosphere}

As indicated in Fig. 7, the friction coefficient has a great influence on the partitioning of water between the surface and deep mantle reservoir; more surface seawater is absorbed in conjunction with smaller friction coefficients (weaker oceanic lithosphere) because the mantle temperature is sufficiently cold so that both the mantle transition zone and upper lower mantle may be worked as large water reservoirs (see Fig. 8). Hence, a large amount of water should be required when the strength of oceanic lithosphere is very weak; however, using the range of friction coefficients suggested by observational data analysis (up to 0.7; Zhong and Watts 2013), the total amount of water in the entire system could be reduced but still be larger than those of the suggested by simple parameterized convection models (e.g., Sandu et al. 2011). However, it should be noted that a weaker oceanic lithosphere is preferable for understanding the plate-like behavior in a dry mantle convection system $\left(\mu_{0}<0.1\right.$; Moresi and Solomatov 1998; Crameri and Tackley 2015). Moreover, in this study, we incorporate the effect of "water weakening" to reduce the yield strength of the oceanic lithosphere under a water-saturated situation.

\section{Total amount of water in the planetary system}

In most geodynamic models with water circulation, the partitioning of water between surface seawater and the deep mantle at the present is assumed to range from 1:1 to 1:2 (Franck and Bounama 2001; Rüpke et al. 2004; Sandu et al. 2011; Korenaga 2011), which is consistent with the results of the mineral physics experiments (Hirschmann 2006). In particular, Franck and Bounama (2001) also suggested that the lifetime of surface seawater may be dependent on the efficiency of regassing caused by plate subduction. However, in this study, the regassing flux is automatically regulated by the water solubility map, including the "choke point" observed at a depth of 150 to $200 \mathrm{~km}$, which is reduced by up to a few orders of magnitude for the regassing flux at this depth. The most important issue in those geodynamic models is that it is difficult to account for the water solubility of mantle minerals, and the water cycle is assumed to involve only degassing for the water release from the deep 
interior to the exosphere and water uptake by the regassing process from the surface to the deep mantle. In addition, degassing is assumed to occur only along mid-ocean ridges but should also occur along island arcs. Furthermore, the scaling relationship is based only on heat transfer in steady-state mantle convection, which is only applicable for cases with less vigorous mantle convection. Therefore, simplified mantle dynamics models with water circulation underestimate both the regassing flux and the degassing flux and therefore require a smaller amount of total water in the entire planetary system ( 3 ocean masses) than the amount inferred from early planetary formation estimates (5 to 15 ocean masses). To avoid these underestimates caused by the assumption of scaling relationships in plate-mantle dynamics, we conducted a series of full mantle convection simulations with water migration, including actual water solubility maps for deep mantle minerals. The results indicate that a large amount of water is needed in the planetary system to achieve a consistent lifetime of surface seawater in the plate-mantle system. This finding is consistent with the estimates of the total amount of water in the entire planetary system inferred from early planetary formation processes.

However, this argument leads to issues related to the sources of the volatile components in the early Earth and their initial amounts (e.g., Albarede 2009). In Nakagawa and Spiegelman (2017), these issues did not affect the initial amount of water in the deep mantle, but the deep mantle should contain a certain amount of water, as illustrated in the water solubility maps of the mantle minerals. These issues remain in models of the early thermal and chemical state of the planetary mantle that do not start from a full magma ocean condition (a fully molten mantle is expected to have been present in the early Earth). To further resolve these issues, the initial state of mantle convection should be seriously examined in a future study that assumes initially fully molten mantle conditions (Lourenço et al. 2016) and then checks the consistency of these conditions with the theoretical estimates of the size of the water reservoir at the surface (Hamano et al. 2013).

Finally, the following evolution of surface seawater associated with a plate-mantle system is proposed; a certain amount of water (volatiles) is delivered to the planet before or after the magma ocean forms (potentially by a giant impact or late veneer accretion, see review by Genda (2016)). After the magma ocean solidifies, surface seawater forms. The partition ratio of water between the surface and the deep mantle is dependent on the water solubility of the deep mantle, which is in turn dependent on the temperature and composition of the early Earth's mantle. Vigorous surface plate motion can transport surface water into the deep mantle; however, because of the high temperatures in the deep mantle, relatively little water stays in the deep mantle. When the mantle is sufficiently cooled by mantle convection, the water transported via plate subduction can be stored in the mantle transition zone and the uppermost lower mantle, thereby gradually reducing the volume of surface water to the present-day amount. Although this conceptual model would be slightly modified by a better understanding of the global-scale mantle water circulation and more accurate water solubility limits of lower mantle mineral assemblage, it is overall a robust model.

\section{Conclusions}

In this study, the evolution of surface seawater in the plate-mantle system with the effects of deep mantle water solubility (e.g., DHMS) is investigated to resolve the controversial issue of the total amount of water in the entire planetary system. The conclusions are as follows:

1. The DHMS solubility field may have a small impact on the evolution of surface seawater but is not very sensitive to the physical mechanism of the mantle water cycle because the mantle water cycle is effective up to a depth of $150 \sim 200 \mathrm{~km}$, which is much shallower than the DHMS solubility field.

2. In numerical simulations, the total amount of water in the entire planetary system should be greater than at least 7 to 12 ocean masses, which is consistent with the water mass estimate based on early planetary formation (Marty 2012; Hamano et al. 2013) and a petrological estimate that includes a realistic maximum $\mathrm{H}_{2} \mathrm{O}$ solubility of mantle material along the slab geotherm (after Iwamori 2007). The main mechanism of the large amount of water required in the entire system is the incorporation of water solubility maps so that the dehydration process can be addressed in numerical mantle convection simulations.

3. DHMS including phase $\mathrm{H}$ may represent an additional water reservoir in the deep mantle and may affect the evolution of surface seawater on the present-day Earth. To better estimate the seawater evolution, more accurate constraints on the stability and amount of water stored in DHMS, phase $\mathrm{H}$, and other hydrous minerals (e.g., $\delta$-AlOOH and pyrite-type $\mathrm{FeOOH}$ ) in the actual mantle are required.

In this study, we successfully computed the evolution of surface seawater in the plate-mantle system caused by hydrous mantle convection and incorporate the solubility fields of hydrous mineral phases in the deep mantle, such as the DHMS. However, it must be noted that due to the global scale of the model, it is very difficult to 

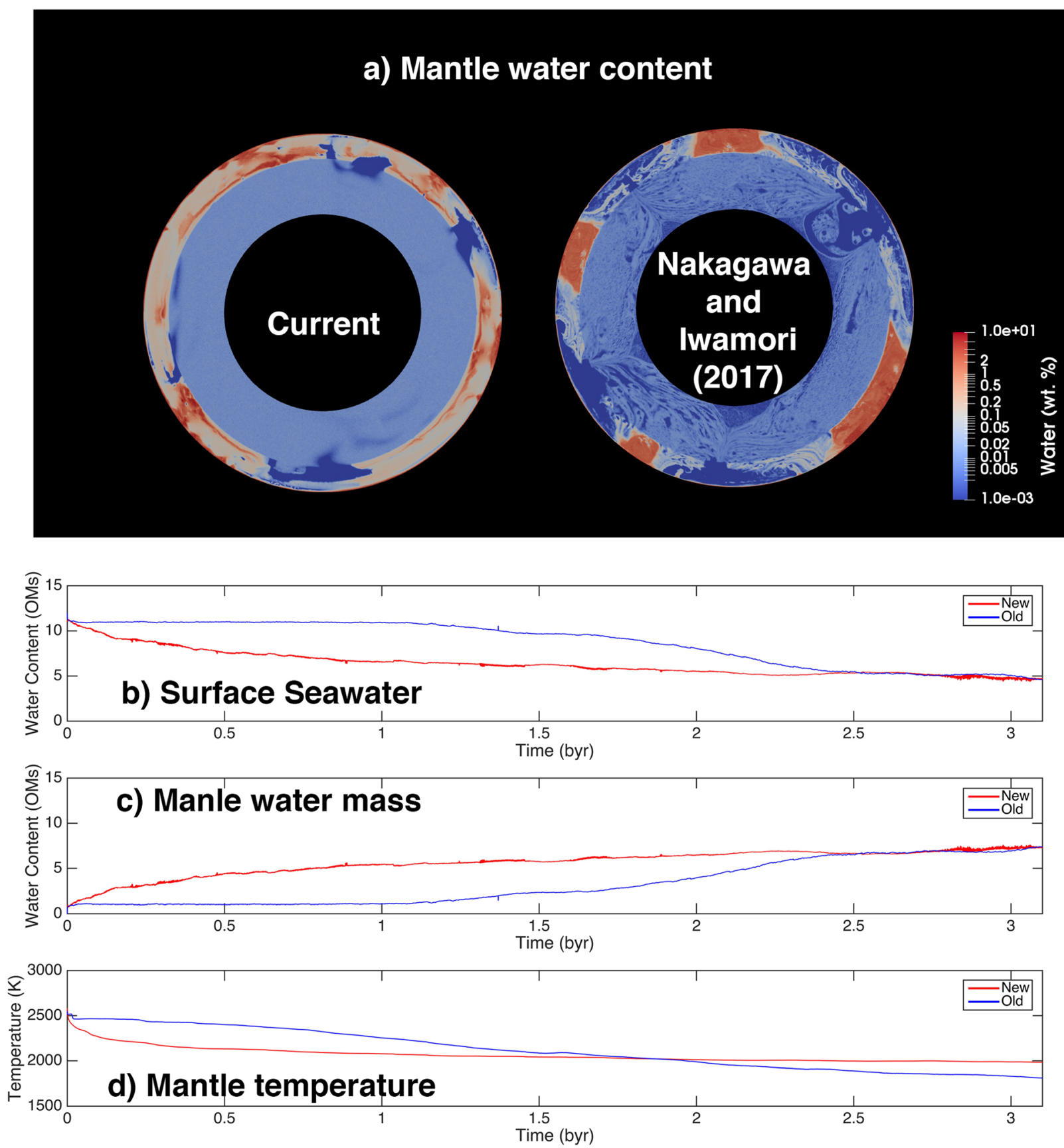

Fig. 10 a Mantle water content taken at 3.1 billion years computed from two different numerical codes without assuming DHMS solubility (left: current version of numerical code; right: the version used in Nakagawa and Iwamori (2017) but corrected for significant issues with the dehydration reaction) and their diagnostics (b evolution of surface seawater, $\mathbf{c}$ mantle water mass, and $\mathbf{d}$ mantle temperature) as a function of time. On the legend of diagnostics plots, new represents a result from the numerical code used in this study and old represents a result from the numerical code used in Nakagawa and Iwamori (2017)

resolve the detailed physical and chemical processes occurring in the mantle wedge as in Nakao et al. (2016, 2018) and van Keken et al. (2011); therefore, some significant improvements are required to reveal the geological and petrological constraints on mantle water evolution, which requires future investigation.

\section{Appendix A}

Comparison between Nakagawa and Iwamori (2017) and the current study

All of the results in this study are very different from those presented in Nakagawa and Iwamori (2017). In particular, as shown in Fig. 6, the sudden change in the 
mantle water content appears to occur on a shorter time scale than that in Nakagawa and Iwamori (2017). As mentioned in the "Methods/Experimental" section, the major difference in the numerical code between these two studies is the use of arbitrary continuous melting (this study) or discretized melting (previous study). Figure 10 shows a comparison of the mantle water content field and diagnostics (surface seawater, mantle water mass, and mantle temperature) between the numerical code used in this study and that used in Nakagawa and Iwamori (2017), which does not assume DHMS solubility. Unfortunately, the original version of the numerical code in Nakagawa and Iwamori (2017) also includes some incorrect treatments of the numerical procedure of the dehydration reaction, which is related to the data transfer in each numerical domain associated with MPI implementations and resetting an array of excess water due to dehydration reaction. These incorrect stuffs are corrected in this study. Following these corrections, both cases yield similar water evolution results. Using the discretized melting approach, the mantle temperature is expected to be much hotter than that with the arbitrary melting approach, which can allow for continuous compositional variations in each tracer because the discretized melting approach is strongly dependent on the heterogeneous distributions of tracer particles as a result of the migrations caused by numerical simulations, which is determined with a probabilistic approach for the degree of melting and is more likely to indicate a smaller degree of melting than the arbitrary melting approach. Due to this difference, the heat transport caused by melt migration is more efficient in the arbitrary melting approach; therefore, different mantle temperature profiles can be found for each case. The mantle water content profiles that correspond to such a difference between these cases are somewhat different for up to a few billion years, but the final results obtained at 4.6 billion years are not very different.

\section{Abbreviations}

CMB: Core-mantle boundary; DHMS: Dense hydrous magnesium silicate

\section{Acknowledgements}

The authors thank Guillaume Richard and an anonymous reviewer for significantly improving the original manuscript. We also thank Tomoeki Nakakuki for providing a numerical module of water migration for mantle convection simulations; Masayuki Nishi for providing information about the water contents of deep mantle hydrous phases; Marc Spiegelman for the fruitful discussion of the evolution of finite volumes of water ocean during TN's sabbatical leave to Lamont-Doherty Earth Observatory, Columbia University, New York City; Paul Tackley for providing his numerical code for mantle convection; and Bjorn Mysen for an invitation to write this manuscript based on our presentation at the $2017 \mathrm{JpGU}$-AGU joint meeting. All numerical computations were performed with the Data Analyzer (DA) system in the JAMSTEC.

\section{Funding}

This work was supported by the JSPS KAKENHI Grant Numbers 16 K05547 and $18 \mathrm{H} 04467$ and by the FLAGSHIP2020 MEXT within the CBSM2 Project "Structure and Properties of Materials in Deep Earth and Planets".

\section{Availability of data and materials}

All simulation data are available upon request to the corresponding author (Takashi Nakagawa), but the simulation code used in this study is the property of the original developer (Paul Tackley) and not open to the public.

\section{Authors' contributions}

TN designed the entire study. HI, RY, and AN provided the parameterized water solubility of hydrated mantle rocks. TN developed a numerical model and carried out all the numerical simulations. TN and $\mathrm{HI}$ wrote the manuscript. All authors interpreted the results of the numerical simulations and read and approved the final manuscript.

\section{Competing interests}

The authors declare that they have no competing interests.

\section{Publisher's Note}

Springer Nature remains neutral with regard to jurisdictional claims in published maps and institutional affiliations.

\section{Author details}

${ }^{1}$ Department of Mathematical Science and Advanced Technology, Japan Agency for Marine-Earth Science and Technology, 3173-25, Showa-machi, Yokohama 236-0001, Japan. ${ }^{2}$ Department of Earth Sciences, University of Hong Kong, Pokfulam Road, Hong Kong, Hong Kong. ${ }^{3}$ Department of Solid Earth Geochemistry, Japan Agency for Marine-Earth Science and Technology, 2-15, Natsushima-cho, Yokosuka 237-0061, Japan. ${ }^{4}$ Department of Earth and Planetary Sciences, Tokyo Institute of Technology, 2-12-1, Ookayama, Meguro, Tokyo 152-8551, Japan. ${ }^{5}$ Earthquake Research Institute, The University of Tokyo, 1-1-1, Yayoi, Bunkyo, Tokyo 113-0032, Japan.

Received: 9 January 2018 Accepted: 23 August 2018

Published online: 14 September 2018

\section{References}

Albarede F (2009) Volatile accretion history of the terrestrial planets and dynamic implications. Nature 461:1227-1233

Appel PWU, Fedo CM, Moorbath S, Myers JS (1998) Recognizable primary volcanic and sedimentary features in a low-strain domain of the highly deformed, oldest known ( 3.7-3.8 Gyr) Greenstone Belt, Isua, West Greenland. Terra Nova 10:57-62

Arcey D, Tric E, Doin MP (2005) Numerical simulations of subduction zones: effect of slab dehydration on the mantle wedge dynamics. Phys Earth Planet Int 149:133-153

Aubaud C, Hirschmann MH, Withers AC, Hervig RL (2008) Hydrogen partitioning between melt, clinopyroxene, and garnet at $3 \mathrm{GPa}$ in a hydrous MORB with 6 wt. \% $\mathrm{H}_{2} \mathrm{O}$. Contrib Mineral Petrol 156:607-625

Christensen UR, Hofmann AW (1994) Segregation of subducted oceanic crust in the convecting mantle. J Geophys Res 99:19867-19884

Condie KC (2016) A planet in transition: the onset of plate tectonics on Earth between 3 and 2 Ga? Geosci Front. https://doi.org/10.1016/j.gsf.2016.09.001

Crameri F, Tackley PJ (2015) Parameters controlling dynamically self-consistent plate tectonics and single-sided subduction in global models of mantle convection. J Geophys Res Solid Earth 120:3680-3706. https://doi.org/10. 1002/2014JB011664

Crowley J, Gérault M, O'Connell RJ (2011) On the relative influence of heat and water transport on planetary dynamics. Earth Planet Sci Lett 310:380-388. https://doi.org/10.1016/j.epsl.2011.08.035

Franck S, Bounama C (2001) Global water cycle and Earth's thermal evolution. J Geodyn 32:231-246

Genda H (2016) Origin of Earth's oceans: an assessment of the total amount history and supply of water. Geochem J 50:27-42

Gerya T, Connolly JAD, Yuen DA (2008) Why terrestrial subduction one-sided? Geology 36:43-46. https://doi.org/10.1130/G24060A.1

Girard J, Amulele G, Farta R, Mohiuddin A, Karato S-I (2016) Shear deformation of bridgmanite and magnesiowüstite aggregates at lower mantle conditions. Science 351:144-147. https://doi.org/10.1126/science.aad3113

Hamano K, Abe Y, Genda H (2013) Emergence of two types of terrestrial planet on solidification of magma ocean. Nature 497:607-610. https://doi.org/10. 1038/nature12163

Hernlund JW, Tackley PJ (2008) Modeling mantle convection in the spherical annulus. Phys Earth Planet Int 171:48-54 
Hirschmann MH (2006) Water, melting, and the deep Earth $\mathrm{H}_{2} \mathrm{O}$ cycle. Annu Rev Earth Planet Sci 34:629-653. https://doi.org/10.1146/annurev.earth.34.031405.125211

Hopkins M, Harrison TM, Manning CE (2008) Low heat flow inferred from >4Gyr zircon suggests Hadean plate boundary interaction. Nature 456:493-496. https://doi.org/10.1038/nature07465

Houser C (2016) Global seismic data reveal little water in the mantle transition zone. Earth Planet Sci Lett 448:94-101. https://doi.org/10.1016/j.epsl.2016.04.018

Iwamori $\mathrm{H}$ (2004) Phase relations of peridotites under $\mathrm{H}_{2} \mathrm{O}$ saturated conditions and ability of subducting plates for transportation of $\mathrm{H}_{2} \mathrm{O}$. Earth Planet Sci Lett 227:57-71. https://doi.org/10.1016/j.epsl.08.013

Iwamori $\mathrm{H}$ (2007) Transportation of $\mathrm{H}_{2} \mathrm{O}$ beneath the Japan arcs and its implications for global water circulation. Chem Geol 239:182-198. https://doi. org/10.1016/j.chemgeo.2006.08.011

Iwamori H, Nakakuki T (2013) Fluid processes in subduction zones and water transport to the deep mantle. In: Karato S-i (ed) Physics and chemistry of the deep mantle. John Wiley \& Sons, Ltd., Oxford, pp 372-391

Karato S, Wu P (1993) Rheology of the upper mantle: a synthesis. Science 260: $771-778$

Karato S-i (2011) Water distribution across the mantle transition zone and its implications for global material circulation. Earth Planet Sci Lett 301:413-423. https://doi.org/10.1016/j.epsl.2010.11.038

Kelbert A, Schultz A, Egbert G (2009) Global electromagnetic induction constraints on transition-zone water content variations. Nature 460:10031006. https://doi.org/10.1038/nature08257

Komabayashi T, Omori S (2006) Internally consistent thermodynamics data set for dense hydrous magnesium silicates up to $35 \mathrm{GPa}$, 1600C: implications for water circulation in the Earth's deep mantle. Phys Earth Planet Int 156:89107. https://doi.org/10.1016/j.pepi.2006.02.002

Korenaga J (2011) Thermal evolution with a hydrating mantle and the initiation of plate tectonics in the early Earth. J Geophys Res 116:B12403. https://doi. org/10.1029/2011JB008410

Korenaga J, Karato S-I (2008) A new analysis of experimental data on olivine rheology. J Geophys Res 113:B02403. https://doi.org/10.1029/2007JB005100

Lourenço D, Rozel A, Tackley PJ (2016) Melting and crustal production helps plate tectonics on Earth-like planets. Earth Planet Sci Lett 439:18-28. https:// doi.org/10.1016/j.epsl.2016.01.024

Lourenço DL, Rozel A, Gerya TV, Tackley PJ (2018) Efficient cooling of rocky planets by intrusive magmatism. Nat Geosci 11:322-327. https://doi.org/10. 1038/s41561-018-0094-8

Marty B (2012) The origins and concentrations of water, carbon, nitrogen and noble gases on Earth. Earth Planet Sci Lett 313-314:56-66. https://doi.org/10. 1016/j.epsl.2011.10.040

Maruyama S, Ikoma M, Genda H, Hirose K, Yokoyama T, Santosh M (2013) The naked planet Earth: most essential pre-requisite for the origin and evolution of life. Geosci Front 4:141-165

Maruyama S, Komiya T (2011) The oldest pillow lavas, 3.8-3.7 Ga from the Isua supracrustal belt, SW Greenland: plate tectonics already begun by $3.8 \mathrm{Ga}$. J Geogr 120:869-876

Maruyama S, Okamoto K (2007) Water transportation from the subducting slab into the mantle transition zone. Gonwana Res 11:148-165. https://doi.org/10. 1016/j.gr.2006.06.001

Mei S, Kohlstedt DL (2000) Influence of water on plastic deformation of olivine aggregates 1. Diffusion creep regime. J Geophys Res 105:21457-31469

Mojzsis SJ, Harrison TM, Pidgeon RT (2001) Oxygen-isotope evidence from ancient zircons from liquid qater at the Earth's surface 4,300 Myr ago. Nature 409:178-81

Moresi L, Solomatov V (1998) Mantle convection with a brittle lithosphere: thoughts on the global tectonic styles of the Earth and Venus. Geophys J Int 133:669-682

Nakagawa T (2017) On the numerical modeling of the deep mantle water cycle in global-scale mantle dynamics: the effects of the water solubility limit of lower mantle minerals. J Earth Sci 28:563-577. https://doi.org/10.1007/ s12583-017-0755-3

Nakagawa T, Iwamori H (2017) Long-term stability of plate-like behavior caused by hydrous mantle convection and water absorption in the deep mantle. J Geophys Res Solid Earth 122. https://doi.org/10.1002/2017JB014052

Nakagawa T, Nakakuki T, Iwamori H (2015) Water circulation and global mantle dynamics: insight from numerical modeling. Geochem Geophys Geosyst 16 1449-1464. https://doi.org/10.1002/GC005071

Nakagawa T, Spiegelman MW (2017) Global-scale water circulation in the Earth's mantle: implications for the mantle water budget in the early earth. Earth Planet Sci Lett 464:189-199. https://doi.org/10.1016/j.epsl. 2017.02.010
Nakagawa T, Tackley PJ (2011) Effects of low-viscosity post-perovskite on thermos-chemical mantle convection in a 3-D spherical shell. Geophys Res Lett 38:L04309. https://doi.org/10.1029/2010GL046494

Nakao A, Iwamori H, Nakakuki T (2016) Effects of water transportation on subduction dynamics: roles of viscosity and density reduction. Earth Planet Sci Lett 454:178-191. https://doi.org/10.1016/j.epsl.2016.08.016

Nakao A, Iwamori H, Nakakuki T, Suzuki YJ, Nakamura H (2018) Role of hydrous lithospheric mantle in deep water transportation and subduction dynamics. Geophys Res Lett. https://doi.org/10.1029/2017GL076953

Nishi M, Irifune T, Tsuchiya J, Tange Y, Nishihara Y, Fujino K, Higo Y (2014) Stability of hydrous silicate at high pressures and water transport to the deep lower mantle. Nat Geosci:224-227. https://doi.org/10.1038/NGEO2074

Nishi M, Kuwayama Y, Tsuchiya J, Tsuchiya T (2017) The pyrite-type high-pressure form of $\mathrm{FeOOH}$. Nature 547:205-208. https://doi.org/10.1038/nature22823

Ohira I, Ohtani E., Kamada S., Hirao N (2016) Formation of phase H- $\delta$-AlOOH solid solution in the lower mantle, Goldschmidt Conference Abstract, 2346

Ohira I, Ohtani E, Sakai T, Miyahara M, Hirao N, Ohishi Y, Nishijima M (2014) Stability of a hydrous $\delta$-phase, $\mathrm{AlOOH}-\mathrm{MgSiO}_{2}(\mathrm{OH})_{2}$, and a mechanism for water transport into the base of lower mantle. Earth Planet Sci Lett 401:1217. https://doi.org/10.1016/j.epsl.05.059

Ohtani $E$ (2015) Hydrous minerals and the storage of water in the deep mantle. Chem Geol 418:6-15. https://doi.org/10.1016/j.chemgeo.2015.05.005

Ohtani E, Amaike Y, Kamada S, Sakamaki T, Hirao N (2014) Stability of hydrous phase $\mathrm{H} \mathrm{MgSiO}_{4}$ under lower mantle conditions. Geophys Res Lett. https:// doi.org/10.1002/2014GL061690

Ohtani E, Toma M, Litasov K, Kubo T, Suzuki A (2001) Stability of dense hydrous magnesium silicate phases and water storage capacity in the transition zone and lower mantle. Phys Earth Planet Int 124:105-117. https://doi.org/10.1016/ S0031-9201(01)00192-03

Panero WR, Pigott JS, Reaman DM, Kabbes JE, Liu Z (2015) Dry (Mg,Fe)SiO perovskite in the Earth's lower mantle. J Geophys Res Solid Earth 120. https:// doi.org/10.1002/2014JB011397

Pearson DG, Brenker FE, Nestola F, McNeill J, Nasdala L, Hutchison MT, Mateev S, Mather K, Silversmit G, Schmitz S, Vekemans B, Vincze L (2014) Hydrous mantle transition zone indicated by ringwoodite included within diamond. Nature 507:221-224. https://doi.org/10.1038/nature13080

Richard G, Bercovici D, Karato S-I (2006) Slab dehydration in the Earth's mantle transition zone. Earth Planet Sci Lett 251:156-167. https://doi.org/10.1016/j. epsl.2006.09.006

Richard G, Monneraeu M, Ingrin J (2002) Is the transition zone an empty water reservoir? Influence from numerical model of mantle dynamics. Earth Planet Sci Lett 205:37-51

Richard GC, Iwamori H (2010) Stagnant slab, wet plumes and Cenozoic volcanism in East Asia. Phys Earth Planet Int 183:280-287. https://doi.org/10.1016/j.pepi. 2010.02.009

Rozel A B, Golabek G J, Jain C, Tackley P J, Gerya T V (2017) Continental crust formation on early Earth controlled by intrusive magmatism. Nature 545: 332-335. doi: https://doi.org/10.1038/nature22042

Rüpke LH, Morgan JP, Hort M, Connolly JAD (2004) Serpentine and the subduction zone water cycle. Earth Planet Sci Lett 223:17-34

Sandu C, Lenardic A, McGovern P (2011) The effects of deep water cycling on planetary thermal evolution. J Geophys Res 116:B12404. https://doi.org/10. 1029/2011 JB008405

Schmandt B, Jacobsen SD, Becker TW, Liu Z, Dueker KG (2014) Dehydration melting at the top of the lower mantle. Science 344:1265-1268. https://doi. org/10.1126/sciecnce.1253358

Tackley PJ (1996) Effects of strongly variable viscosity on three-dimensional compressible convection in planetary mantles. J Geophys Res Solid Earth 101:3311-3322

Tackley PJ (2008) Modelling compressible mantle convection with large viscosity contrast in a three-dimensional spherical shell using the yin-yang grid. Phys Earth Planet Int 171:7-18

Valley JW, Cavosie AJ, Ushikubo T, Reinhard DA, Lawrence DF, Larson DJ, Clifton PH, Kelly TF, Wilde SA, Moser DE, Spicuzza MJ (2014) Hedean age for a postmagma-ocean zircon confirmed by atom-probe tomography. Nat Geosci 7: 219-223

van Keken PE, Hacker BR, Syracuse EM, Abers GA (2011) Subduction factory: 4. Depth-dependent flux of $\mathrm{H} 2 \mathrm{O}$ from subducting slabs worldwide. J Geophys Res 116:B01401. https://doi.org/10.1029/2010jb007922

Walter MJ, Thomson AR, Wang W, Lord OT, Ross J, McMahon SC, Baron MA, Melekhova E, Kleppe AK, Kohn SC (2015) The stability of hydrous silicates in 
Earth's lower mantle: Experimental constraints from the systems MgO-SiO2$\mathrm{H} 2 \mathrm{O}$ and $\mathrm{MgO}-\mathrm{Al} 2 \mathrm{O} 3-\mathrm{SiO} 2-\mathrm{H} 2 \mathrm{O}$. Chem Geol 418:16-29. https://doi.org/10. 1016/j.chemgeo.2015.05.001

White WM, Hofmann AW (1982) Sr and Nd isotope geochemistry of oceanic basalt and mantle evolution. NAature 296:821-825

Wilson CR, Spiegelman M, van Keken PE, Hacker BR (2014) Fluid flow in subduction zones: the role of solid rheology and compaction pressure. Earth Planet Sci Lett 401:261-274. https://doi.org/10.1016/j.epsl.2014.05.052

Xie S, Tackley PJ (2004) Evolution of U-Pb and Sm-Nd systems in numerical models of mantle convection. J Geophys Res 109:B11204. https://doi.org/10. 1029/2004JB003176

Yamazaki D, Karato S (2001) Some mineral physics constraints on the rheology and geothermal structure of Earth's lower mantle. Am Mineral 86:385-301

Zhong S, Watts AB (2013) Lithospheric deformation induced by loading of the Hawaiian Islands and its implications for mantle rheology. J Geophys Res Solid Earth 118:6025-6048. https://doi.org/10.1002/2013JB010408

\section{Submit your manuscript to a SpringerOpen ${ }^{\circ}$ journal and benefit from:}

- Convenient online submission

- Rigorous peer review

- Open access: articles freely available online

High visibility within the field

- Retaining the copyright to your article

Submit your next manuscript at $\boldsymbol{\nabla}$ springeropen.com 